\title{
UNIVERSITY OF

\section{Meta-study: Analysis of thermoelectric figure of merit parameters for silicides with various doping agents}

\author{
Marcus Newton ${ }^{1, *}$, Simon White ${ }^{2}$, Asher Gomez ${ }^{3}$, Caleb Estherby \\ Faculty of Science, University of Technology, Sydney, P.O. Box 123, Australia \\ 1 Marcus.Newton@student.uts.edu.au \\ 2 Simon.White@student.uts.edu.au \\ 3 Asher.Gomez@student.uts.edu.au \\ 4 Caleb.Estherby@student.uts.edu.au \\ * Author to whom correspondence should be addressed: Marcus.Newton@student.uts.edu.au
}

DOI: http://dx.doi.org/10.5130/pamr.v3i0.1411

\begin{abstract}
Thermoelectric (TE) materials are increasingly promising for power generation in medium to high-temperature environments. Recent research on thermoelectric generators (TEGs) has determined the thermodynamic properties which impact the total efficiency and figure of merit (ZT) of these materials. A large Seebeck coefficient, high electrical conductivity and low thermal conductivity optimise ZT. This meta-study investigates silicides for potential TEG applications due to their high chemical stability and higher natural abundance than other TE materials. Data on the thermoelectric properties of $\mathrm{CrSi}_{2}, \mathrm{FeSi}_{2}, \mathrm{Mg}_{2} \mathrm{Si}$ and $\mathrm{MnSi}_{2}$, with a range of dopants, was sourced from a wide scope of literature and is analysed. The above thermodynamic properties contributing to ZT for each of these materials are graphed between 300 and $1000 \mathrm{~K}$. It was found that chromium silicides are most effective at a temperature range of 600-800 K, and undoped magnesium silicides are most effective around $900 \mathrm{~K}$. Oxide addition to $\beta$-FeSi2 produced relatively high $\mathrm{ZT}$ scores $(\mathrm{ZT} \approx 0.5)$ among iron silicides. Rhenium substitution in manganese silicides produced a maximum figure of merit (1.05) at $900 \mathrm{~K}$. Supersaturation via liquid quenching was determined to maintain high rhenium substitution and this technique may be the key to further improving the thermoelectric properties of other silicides.
\end{abstract}

Keywords: Thermoelectric; Silicide; Figure of Merit; ZT; Meta-study; Doped 


\section{INTRODUCTION}

With the exponential growth of the global population and increased use of industrial technology comes a high demand for energy production. With an established consensus that climate change is caused by humans, it is imperative that we move away from traditional means of power generation, especially fossil fuels (IEA.org, 2016). However, since many developing nations rely heavily on non-renewable energy sources, reducing heat loss and power conversion inefficiencies for these power generators remain highly important. Indeed, a large percentage of heat energy is lost during the production of power in coal plants and many other power generation systems including car exhaust, nuclear power and home heating (Frobenius et al. 2016). One way to increase the efficiency of the current production is to capture waste heat with thermoelectric generators (TEGs) to collect this heat and convert it to useful energy. This can be implemented in any situation where there is a temperature differential. As TEGs are solid state devices they are silent, reliable and have no moving parts (Rowe, D. M. 1995).

Thermoelectric materials of relatively low cost (silicides, oxides, skutterudites) and high chemical stability (silicides, oxides) show promise for industrial applications where cost and durability are important. Advances in nanofabrics, such as superlattices, nanocomposites and nanowires have expanded options for further optimising TEGs (Ozden et al. 2015).

Chromium silicides have drawn interest due to their very high oxidation resistance and stability, relatively high electrical conduction and potential high Seebeck coefficient (Ohishi et al. 2015). The low cost and high supply of iron are two of the main reasons to consider iron disilicides as another potential candidate for thermoelectric power generation. There exist two phases of $\mathrm{FeSi}_{2}$, the lesser studied $\alpha$-phase metal, which boasts effective thermoelectric power generation at $1200 \mathrm{~K}$ (Fedorov et al. 2007), and the $\beta$-phase semiconductor which is able to work at more practical and common temperatures, below $1200 \mathrm{~K}$. For these reasons, $\beta$-FeSi 2 is of primary interest in this report. $\alpha-\mathrm{FeSi}_{2}$ may indeed possess opportunities for thermoelectric generation but only in super-high temperature environments such as high-temperature gas-cooled nuclear reactors (HTGC) with temperatures conceptually reaching over $1000 \mathrm{~K}$ during operation (GNP Industry Alliance, 2010). Being a semiconductor, doping of $\beta-\mathrm{FeSi}_{2}$ can bring great technological advantages to the material, specifically increased efficiency. In this paper, $\beta$-FeSi2 doped with $\mathrm{Zn}, \mathrm{Co}, \mathrm{Co} / \mathrm{Ge}$ and $\mathrm{Nb}$, as well as rare earth oxides $\mathrm{SmO}_{3}$ and $\mathrm{ErO}_{2}$ are compared and analysed (Sugihara \& Morikawa 2011).

Magnesium silicides are a promising candidate for TEG applications, as silicon, magnesium and aluminium are highly abundant, non-toxic and low-density constituent elements (Battiston et al. 2013) (Taylor 1964). Initially, the focus was to find $\mathrm{Mg}_{2} \mathrm{Si}$ containing only $\mathrm{Al}$ dopant, however, research here is limited. We therefore broadened the scope to include Al-doped materials with other substituents, including $\mathrm{Zn}$ and conductive glass.

Yamamoto et al.'s research show that rhenium substitution in $\mathrm{MnSi}_{2}$ greatly reduces the lattice thermal conductivity without affecting the electron transport properties (Yamamoto et al. 2016). Rhenium was compared with tungsten because they are of similar size and weight and they are both transition metals. Additionally, Truong et al.'s research was of interest as it compared tungsten, chromium and molybdenum substitution in $\mathrm{MnSi}_{2}$, with the goal to possibly reduce the lattice thermal conductivity by creating large mass fluctuations and lattice distortion owing to their size differences compared with the matrix element Mn (Truong et al. 2015). 


\section{PAM Review 2016}

To compare the relative performance of a material at a particular temperature, the unitless thermoelectric figure of merit $(\mathrm{ZT})$ is used:

$$
Z T=\frac{\varepsilon^{2} T}{k}
$$

Where $\sigma$ is electrical conductivity, $\mathrm{S}$ is Seebeck Coefficient, $\mathrm{T}$ is system temperature and $\mathrm{k}$ is thermal conductivity.

The Seebeck coefficient is a metric which quantifies a material's ability to readily convert heat into electricity. It is an intrinsic property of the material dependent on structural, thermodynamic and chemical properties, such as molecular structure, charge carrier concentration and effective mass.

Electrical conductivity is the measure of a material's ability to support the transport of electrical charge. Eq. 1 specifies that high conductivity is important for an effective thermoelectric material.

Thermal conductivity is the ability to transfer heat through a material. To obtain a high figure of merit, low total thermal conductivity $(\mathrm{k})$ is required. However, decreasing thermal conductivity can often decrease electrical conductivity. Phonon scattering can be used as a way to overcome this. Complex periodic crystalline structures and point defects (such as vacancies, interstitials, alloying) slow down phonon propagation through the medium by scattering, while electrons can still flow freely. This type of material is referred to as an electron-crystal/phonon-glass and has the effect of maintaining high electrical conductivity while reducing thermal conductivity (Snyder \& Toberer 2008).

\section{METHOD}

The purpose of this meta-study is to obtain and compare a wide range of thermoelectric doped and undoped silicides to determine, via the figure of merit, which material has the most potential in medium to high-temperature environments. Silicides were chosen as we identified them as a promising field of study and there was an ample amount of recent research done in that area. The first stage of the study required the selection of a range of journal articles. This was undertaken using a number of UTS databases including Web of Science, Science Direct, Scopus and external journal databases such as aps.org (American Physical Society). Recently published papers (post-2001) were chosen to highlight to modern advancements and ensure the technologies used are comparable and relevant to current manufacturing abilities. For the selection of papers to analyse, our chosen criterion required that the reviewed articles must include silicides containing one or more substituents. It was determined $\mathrm{CrSi}_{2}$, $\mathrm{FeSi}_{2}, \mathrm{Mg}_{2} \mathrm{Si}$ and $\mathrm{MnSi}_{2}$ were relevant materials.

In the second stage, data points in the second stage were reverse engineered from figures in the selected journals using "Web Plot Digitiser" (Arohatgi.info 2016). This was required as raw data was unavailable. Thermodynamic properties $(\sigma, \mathrm{S}$ and $\mathrm{k})$ were then plotted against temperature $(\mathrm{T})$ between 300 and $1000 \mathrm{~K}$ for comparison between materials. A limited number of papers were reviewed (2-3) by each of the four authors due to time constraints, and to ensure each paper was interpreted correctly.

For the comparison of chromium silicide, three papers were reviewed. The effects of chromium-molybdenum (Ohishi et al. 2015), chromium-titanium substitution (Karuppaiah et al. 2013) and chromium-manganese/silicon-aluminium co-substitution (Gorsse \& Chevalier 2013) were analysed. 
Three papers were reviewed for the comparison between $\beta$-phase iron disilicides. Ito et al. investigated the lesser studied p-type dopant, $\beta$-FeSi2. P-type doped variants $\mathrm{Fe}_{1-\mathrm{x}} \mathrm{M}_{\mathrm{x}} \mathrm{Si}_{2}(\mathrm{M}=\mathrm{Ti}, \mathrm{Nb}$ or $\mathrm{Zr}$ with $0<\mathrm{x}<0.06$ ) were synthesised. $\mathrm{Sm}_{2} \mathrm{O}_{3}$ and $\mathrm{Er}_{2} \mathrm{O}_{3}$ doped $\beta$-Fe ${ }_{0.95} \mathrm{Co}_{0.05} \mathrm{Si}_{2}$ were investigated by Sugihara \& Morikawa. Kim et al. investigated n- and p-type $\beta$-FeSi2 dopants, with $\mathrm{Fe}_{0 .}{ }_{95} \mathrm{Co}_{0.05} \mathrm{Si}_{2}$ and $\mathrm{Fe}_{0.95} \mathrm{Co}_{0.05} \mathrm{Si}_{1.958} \mathrm{Ge}_{0.042}$ variants yielding the greatest thermoelectric performance increases.

Three journal articles revealing the thermoelectric properties of Al-doped magnesium silicide were reviewed. $\mathrm{Hu}$ et al. synthesised their material with commercially pure AZ31 magnesium alloy chips. Note that ' $\mathrm{Mg}(\mathrm{AZ})_{2} \mathrm{Si} 1 \mathrm{st}$ ' and ' $\mathrm{Mg}(\mathrm{AZ})_{2} \mathrm{Si} 2$ nd' refer to two materials with the AZ31 dopant, but deviation can occur with commercial products. Battison et al. doped $\mathrm{Mg}_{2} \mathrm{SiAl}_{\mathrm{x}}(\mathrm{x}=0.005$ and 0.01). Satyala et al. doped $\mathrm{Mg}_{2} \mathrm{Si}$ with 2 -at $\% \mathrm{Al}$ and 0.25 -vol\% of $\mathrm{Mg}-\mathrm{Si}-\mathrm{B}-\mathrm{R}$ based conductive glassfrit ( $\mathrm{R}$ being an alkaline earth metal). Undoped $\mathrm{Mg}_{2} \mathrm{Si}$ is also included in Fig. 1.3 from Battison et al.'s results.

Two journal articles were also analysed to demonstrate the thermoelectric properties of manganese silicide when substituted with Re and W. Yamamoto et al. synthesised their material with powders of near-pure elements, $\mathrm{Mn}, \mathrm{Si}$ and Re, to synthesis their supersaturated $\mathrm{Mn}_{36.4-\mathrm{x}} \mathrm{Re}_{\mathrm{x}} \mathrm{Si}_{63.6}$ samples. Truong et al. used powders of $\mathrm{W}, \mathrm{Al}$ and $\mathrm{Ge}$ for substitution in $\mathrm{MnSi}_{2}$. Unsubstituted $\mathrm{MnSi}_{2}$ was also included from Yamamoto et al.'s results.

Finally, a comparison between the materials and doping concentrations was made with respect to electrical and thermal conductivity, Seebeck coefficient and figure of merit to determine the most effective thermoelectric material. The two best performing materials from each of the four investigations were individually selected and a comparison was made in the final ZT graph (Fig. 5).

\section{RESULTS AND DISCUSSION}

\subsection{Electrical conductivity}

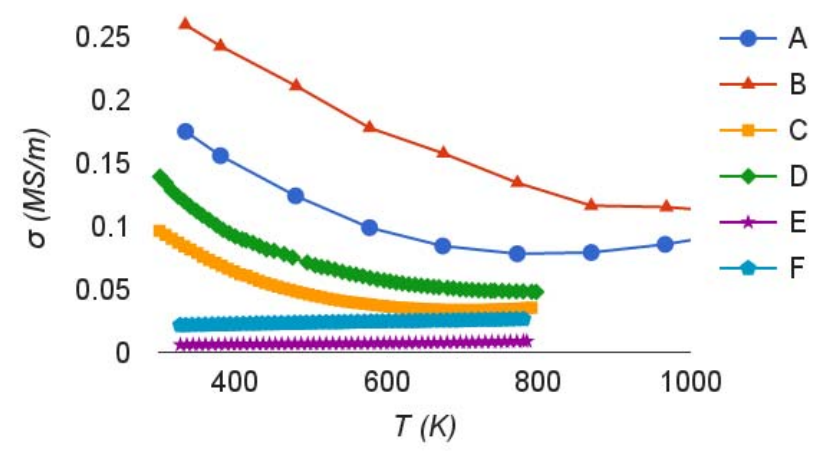

Fig. 1.1 Electrical conductivities of $\mathrm{CrSi}_{2}$ with various dopants: $\mathrm{Cr}_{0.9} \mathrm{Mo}_{0.1} \mathrm{Si}_{2}(\mathrm{~A}), \mathrm{Cr}_{0.7} \mathrm{Mo}_{0.3} \mathrm{Si}_{2}(\mathrm{~B}), \mathrm{Cr}_{0.975} \mathrm{Mn}_{0.025} \mathrm{Si}_{1.975} \mathrm{Al}_{0.025}$ (C), $\mathrm{Cr}_{0.9} \mathrm{Mn}_{0.1} \mathrm{Si}_{1.9} \mathrm{Al}_{0.1}$ (D), $\mathrm{Cr}_{0.94} \mathrm{Ti}_{0.06} \mathrm{Si}_{2}(\mathrm{E})$ and $\mathrm{Cr}_{0.85} \mathrm{Ti}_{0.15} \mathrm{Si}_{2}$ (F)

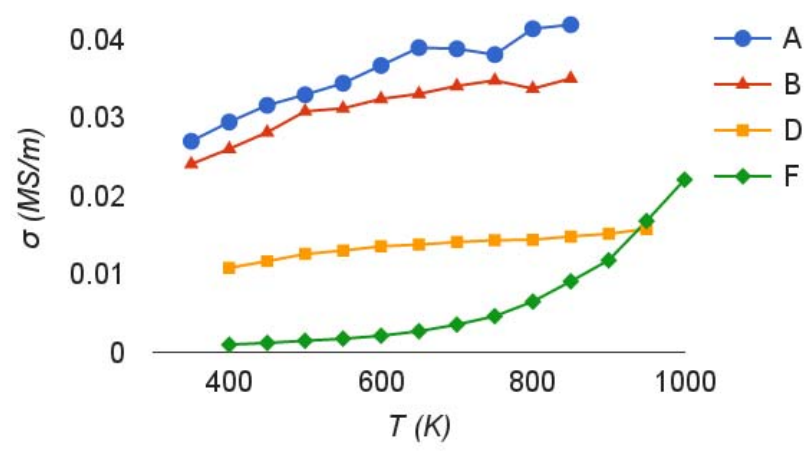

Fig. 1.2 Electrical conductivities of $\mathrm{FeSi}_{2}$ with various dopants: $\beta$ $\mathrm{FeSi}_{2}$ w/ $\mathrm{Sm}_{2} \mathrm{O}_{3}$ (A), $\beta-\mathrm{FeSi}_{2}$ w/ $\mathrm{Er}_{2} \mathrm{O}_{3}$ (B), $\mathrm{Fe}_{0.95} \mathrm{Co}_{0.05} \mathrm{Si}_{2}$ (D) and $\mathrm{Fe}_{0.96} \mathrm{Nb}_{0.04} \mathrm{Si}_{2}(\mathrm{~F})$ 


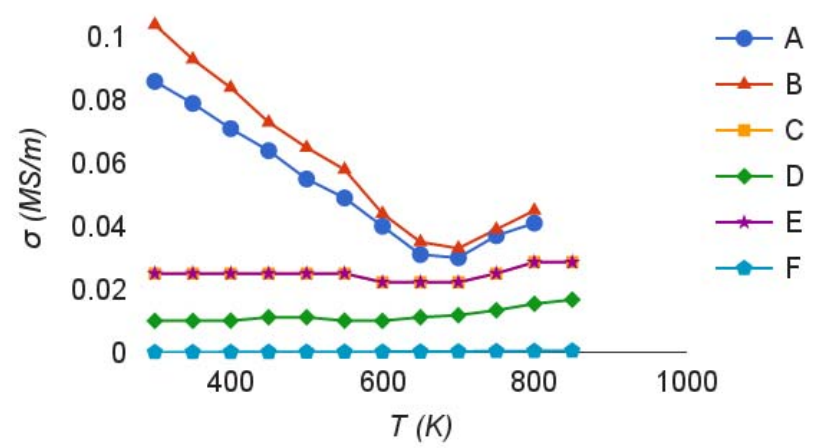

Fig. 1.3 Electrical conductivities of $\mathrm{Mg}_{2} \mathrm{Si}$ with various dopants: $\operatorname{Mg}(\mathrm{AZ})_{2} \mathrm{Si} 1$ st (A), $\mathrm{Mg}(\mathrm{AZ})_{2} \mathrm{Si}$ 2nd (B), $\mathrm{Mg}_{2} \mathrm{SiAl}_{0.01}(\mathrm{C})$, $\mathrm{Mg}_{2} \mathrm{SiAl}_{0.005}$ (D), Al-doped $\mathrm{Mg}_{2} \mathrm{Si}$ w/ glass (E) and undoped $\mathrm{Mg}_{2} \mathrm{Si}(\mathrm{F})$

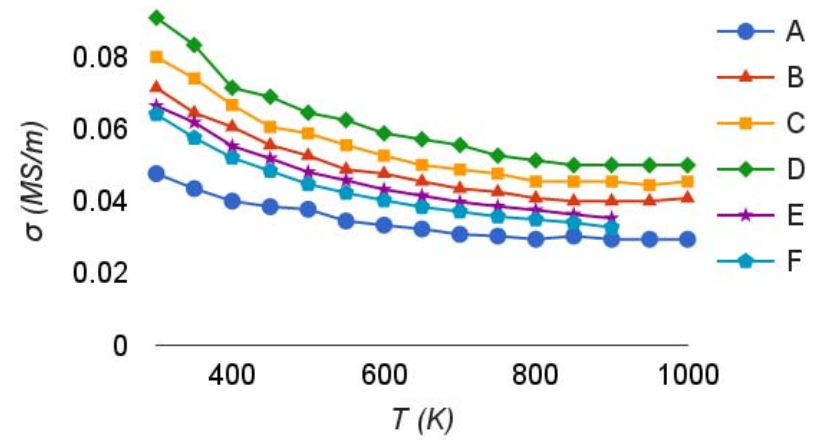

Fig. 1.4 Electrical conductivities of $\mathrm{MnSi}_{2}$ with various dopants: $\mathrm{Mn}_{36.4} \mathrm{Si}_{63.6}(\mathrm{~A}), \mathrm{Mn}_{32.4} \mathrm{Re}_{4} \mathrm{Si}_{63.6}(\mathrm{~B}), \mathrm{Mn}_{30.4} \mathrm{Re}_{6} \mathrm{Si}_{63.6}(\mathrm{C})$, $\mathrm{Mn}_{28.4} \mathrm{Re}_{8} \mathrm{Si}_{63.6}(\mathrm{D}), \mathrm{Mn}_{0.98} \mathrm{~W}_{0.2} \mathrm{Si}_{1.75} \mathrm{Ge}_{0.02}(\mathrm{E})$ and $\mathrm{Mn}_{0.98} \mathrm{~W}_{0.2} \mathrm{Si}_{1.73} \mathrm{Ge}_{0.02} \mathrm{Al}_{0.02}(\mathrm{~F})$

As discussed, high conductivity is important to maximise ZT. Fig. 1.1-4 show electrical conductivity as a function of temperature for all silicides. Most notably, it can be seen that electrical conductivity tends to decrease with increasing temperature, except for iron silicide which increases with increasing temperature. $\mathrm{Cr}_{0.7} \mathrm{Mo}_{0.3} \mathrm{Si}_{2}$ maintains the highest electrical conductivity value across all temperatures.

Consistent among all $\mathrm{CrSi}_{2}$ papers, Fig. 1.1 shows increased substitution into the chromium sites increases electrical conductivity. As explained by Ohishi et al., this is due to increased carrier concentration with the addition of the dopant. The decrease of conduction as temperature increased is also consistent across dopants, due to increased carrier-phonon scattering at higher temperatures (Gorsse \& Chevalier, 2013). Highly doped molybdenum $\left(\mathrm{Cr}_{0.7} \mathrm{Mo}_{0.3} \mathrm{Si}_{2}\right)$ has the greatest electrical conductivity with, $\sigma \approx 0.26 \times 10^{6} \mathrm{~S} / \mathrm{m}$ at $300 \mathrm{~K}$ which reduced to $\sigma \approx 0.15 \times 10^{6} \mathrm{~S} / \mathrm{m}$ at $1000 \mathrm{~K}$. Increased doping with $\mathrm{Mn}$ and $\mathrm{Al}\left(\mathrm{Cr}_{0.9} \mathrm{Mn}_{0.1} \mathrm{Si}_{1.9} \mathrm{Al} \mathrm{l}_{0.1}\right)$, also found the greatest relative electrical conductivity, $\sigma \approx 0.15 \times 10^{6} \mathrm{~S} / \mathrm{m}$, at $300 \mathrm{~K}$ which follows the same trend and reduces to $\sigma \approx 0.07 \times 10^{6}$ $\mathrm{S} / \mathrm{m}$ at $800 \mathrm{~K}$. Titanium doped $\mathrm{CrSi}_{2}$ shows an alternate trend where $\sigma$ is relatively low and increases linearly with temperature. This is explained by the small grain size and low density (about 70\%) which increases the charge carrier scattering (Karuppaiah et al. 2013).

The Zr-doped FeSi specimen in Fig. 1.2 was unable to be graphed because the material electrical resistance is about zero (Ito et. al.). Hence, finding the reciprocal would possibly lead to inaccurate electrical conductivity values. We are informed that the electrical conductivity of the $\mathrm{Zr}$ doped material ranges between $0.043 \mathrm{MS} / \mathrm{m}$ and $0.071 \mathrm{MS} / \mathrm{m}$ at $700 \mathrm{~K}$ and $1173 \mathrm{~K}$, respectively. This places the material as the best electrically conducting material within the iron silicides. The oxidecontaining $\beta-\mathrm{FeSi}_{2}$, with the addition of $\mathrm{Sm}_{2} \mathrm{O}_{3}$ and $\mathrm{Er}_{2} \mathrm{O}_{3}$, also performed well, with substantially greater electrical conductivities than the $\mathrm{Nb}$-doped and Co-doped materials, as seen in Fig. 1.2. Sugihara et al. increased the performance of $\beta-\mathrm{FeSi}_{2}$, by combining with rare earth oxides, achieving a peak $0.4 \mathrm{MS} / \mathrm{m}$ for $\mathrm{Sm}_{2} \mathrm{O}_{3}$. All materials appeared to exhibit rising trendlines. Most notably, the $\mathrm{Nb}$ doped material showed a trendline with which the gradient increased as temperature increased. This suggests that the $\mathrm{FeSi}_{2}$ materials tend to conduct electricity better at higher temperature levels, in contrast to $\mathrm{CrSi}_{2}, \mathrm{Mg}_{2} \mathrm{Si}$ and $\mathrm{MnSi}_{2}$. 
Fig. 1.3 shows significantly high electrical conductivity $(\sigma=0.1 \mathrm{MS} / \mathrm{m}$ and $0.04 \mathrm{MS} / \mathrm{m}$ ) for $\mathrm{Mg}(\mathrm{AZ})_{2} \mathrm{Si}$ between temperatures of 300 and $600 \mathrm{~K}$, and behaves differently to the other silicides, possibly due to the small amount of $\mathrm{Zn}$ dopant. Electrical conductivity for $\mathrm{Mg}_{2} \mathrm{SiAl}_{0.01}$ and $\mathrm{Mg}_{2} \mathrm{SiAl}_{0.005}$ were lower than $\mathrm{Mg}(\mathrm{AZ})_{2} \mathrm{Si}$ and $\mathrm{Al} \mathrm{Mg}_{2} \mathrm{Si}$ w/ glass across all temperatures.

The electrical conductivity of all manganese silicides in Fig. 1.4 decrease as temperature increases and shape was consistent despite completely different dopant materials. At low temperatures, the presence of dopant significantly increases electrical conductivity compared to undoped $\mathrm{MnSi}_{2}$. $\mathrm{Mn}_{28.4} \mathrm{Re}_{8} \mathrm{Si}_{63.6}$ had the highest relative conductivity of 0.9 to $0.6 \mathrm{MS} / \mathrm{m}$ over 300 to $1000 \mathrm{~K}$.

\subsection{Seebeck coefficient}

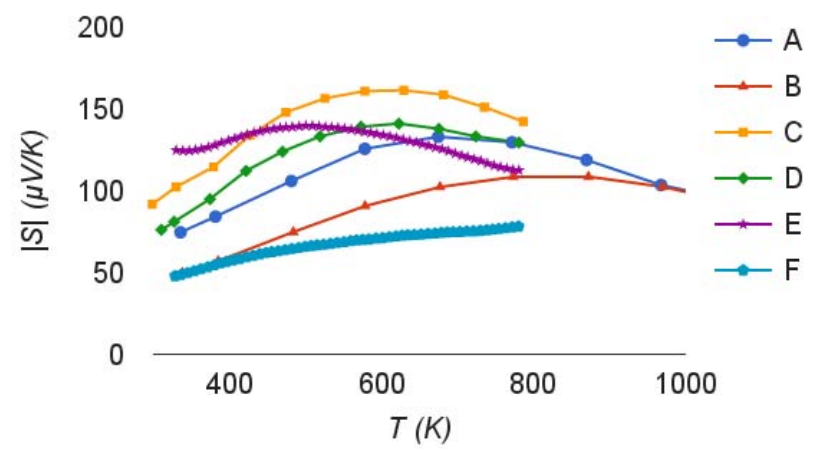

Fig. 2.1 Seebeck coefficient of $\mathrm{CrSi}_{2}$ with various dopants:

$\mathrm{Cr}_{0.9} \mathrm{Mo}_{1 .} \mathrm{Si}_{2}$ (A), $\mathrm{Cr}_{0.7} \mathrm{Mo}_{0.3} \mathrm{Si}_{2}$ (B), Cr0.975 Mn0.025Si1.975 $\mathrm{Al}_{0.025}$

(C), $\mathrm{Cr}_{0.9} \mathrm{Mn}_{0.1} \mathrm{Si}_{1.9} \mathrm{Al}_{0.1}$ (D), $\mathrm{Cr}_{0.94} \mathrm{Ti}_{0.06} \mathrm{Si}_{2}$ (E) and

$\mathrm{Cr}_{0.85} \mathrm{Ti}_{0.15} \mathrm{Si}_{2}(\mathrm{~F})$

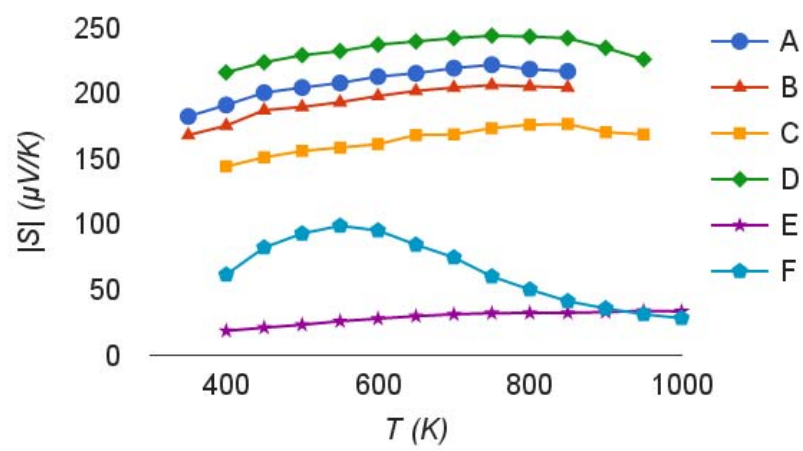

Fig. 2.2 Seebeck coefficient of $\mathrm{FeSi}_{2}$ with various dopants: $\beta$ -

$\mathrm{FeSi}_{2}$ w/ $\mathrm{Sm}_{2} \mathrm{O}_{3}$ (A), $\beta$-FeSi2 w/ $\mathrm{Er}_{2} \mathrm{O}_{3}$ (B),

$\mathrm{Fe}_{0.95} \mathrm{Co}_{0.05} \mathrm{Si}_{1.958} \mathrm{Ge}_{0.042}$ (C), $\mathrm{Fe}_{0.95} \mathrm{Co}_{0.05} \mathrm{Si}_{2}$ (D), $\mathrm{Fe}_{0.94} \mathrm{Zr}_{0.06} \mathrm{Si}(\mathrm{E})$

and $\mathrm{Fe}_{0.96} \mathrm{Nb}_{0.04} \mathrm{Si}_{2}(\mathrm{~F})$
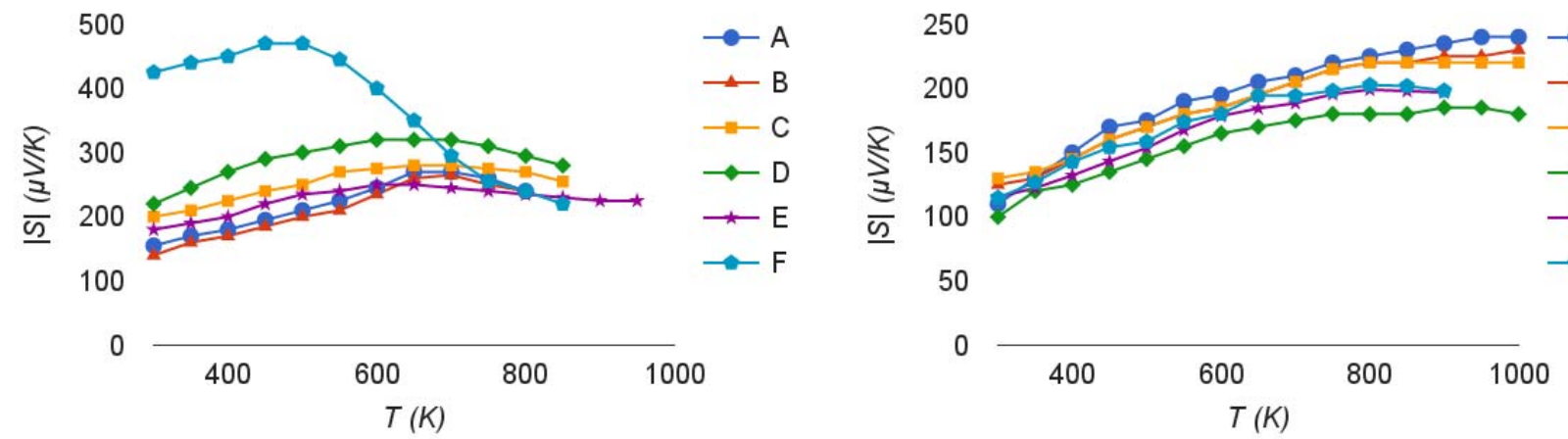

Fig. 2.3 Seebeck coefficient of $\mathrm{Mg}_{2} \mathrm{Si}$ with various dopants: $\mathrm{Mg}(\mathrm{AZ})_{2} \mathrm{Si} 1$ st (A), $\mathrm{Mg}(\mathrm{AZ})_{2} \mathrm{Si}$ 2nd (B), $\mathrm{Mg}_{2} \mathrm{SiAl}_{0.01}$ (C), $\mathrm{Mg}_{2} \mathrm{SiAl}_{0.005}$ (D), Al-doped $\mathrm{Mg}_{2} \mathrm{Si}$ w/ glass (E) and undoped $\mathrm{Mg}_{2} \mathrm{Si}(\mathrm{F})$

Fig. 2.4 Seebeck coefficient of $\mathrm{MnSi}_{2}$ with various dopants:

$\mathrm{Mn}_{36.4} \mathrm{Si}_{63.6}(\mathrm{~A}), \mathrm{Mn}_{32.4} \mathrm{Re}_{4} \mathrm{Si}_{63.6}$ (B), $\mathrm{Mn}_{30.4} \mathrm{Re}_{6} \mathrm{Si}_{63.6}(\mathrm{C})$,

$\mathrm{Mn}_{28.4} \mathrm{Re}_{8} \mathrm{Si}_{63.6}(\mathrm{D}), \mathrm{Mn}_{0.98} \mathrm{~W}_{0.2} \mathrm{Si}_{1.75} \mathrm{Ge}_{0.02}(\mathrm{E})$ and

$\mathrm{Mn}_{0.98} \mathrm{~W}_{0.2} \mathrm{Si}_{1.73} \mathrm{Ge}_{0.02} \mathrm{Al}_{0.02}(\mathrm{~F})$

Fig. 2.1-4 show Seebeck coefficient as a function of temperature for all silicides. The highest Seebeck coefficient for doped materials was $300 \mu \mathrm{V} / \mathrm{K}$ at $650 \mathrm{~K}$ for $\mathrm{Mg}_{2} \mathrm{SiAl}_{0.005}$. 


\section{PAM Review 2016}

In Fig. 2.1, Seebeck coefficient is compared among chromium silicides. $\mathrm{Cr}_{0.975} \mathrm{Mn}_{0.025} \mathrm{Si}_{1.975} \mathrm{Al}_{0.025}$ and $\mathrm{Cr}_{0.9} \mathrm{Mn}_{0.1} \mathrm{Si}_{1.9} \mathrm{Al}_{0.1}$ were found to have $\mathrm{S}_{\max }=160$ and $140 \mu \mathrm{V} / \mathrm{K}$ at 600 and $650 \mathrm{~K}$, respectively. $\mathrm{Cr}_{0.9} \mathrm{Mo}_{0.1} \mathrm{Si}_{2}$ and $\mathrm{Cr}_{0.7} \mathrm{Mo}_{0.3} \mathrm{Si}_{2}$ were found to have $\mathrm{S}_{\max }=140$ and $100 \mu \mathrm{V} / \mathrm{K}$ at 700 and $900 \mathrm{~K}$, respectively. Seebeck coefficient decreases as doping content increases for all chromium silicides. This reduction in $\mathrm{S}$ is due to decreased hole mobility, which is more pronounced at higher temperatures (Gorsse \& Chevalier 2013). Temperature value for $S_{\max }$ was also found to decrease (shift left) with increased doping. Ti-doped $\mathrm{CrSi}_{2}$ has a much lower Seebeck coefficient but increased doping also decreased $\mathrm{S}$.

Fig. 2.2 shows that the Seebeck coefficient of the n-type $\beta$-FeSi2 materials (A through $\mathrm{D}$ ) varies less than $50 \mu \mathrm{V} / \mathrm{K}$ between 300 and $1000 \mathrm{~K}$. Nb-doped $\mathrm{FeSi}_{2}$, in contrast to the other iron silicides, shows a peak Seebeck coefficient of $100 \mu \mathrm{V} / \mathrm{K}$ at $550 \mathrm{~K}$, suggesting a narrow optimal temperature range for the material $(450$ to $650 \mathrm{~K}$ ). The n-type materials (A through $\mathrm{D}$ ) outperform the two p-type materials $(\mathrm{E}, \mathrm{F})$.

All magnesium silicides in Fig. 2.3 show a decline in Seebeck coefficient magnitude from 700 to $900 \mathrm{~K}$. Compared to undoped $\mathrm{Mg}_{2} \mathrm{Si}$, smaller amounts of Al-dopant improve Seebeck coefficient at temperatures above $650 \mathrm{~K}$ for $\mathrm{Mg}_{2} \mathrm{SiAl}_{0.005}$.

$\mathrm{MnSi}_{2}$ curves all follow similar trends, as the Seebeck coefficient value for $\mathrm{MnSi}_{2}$ consistently increases as temperature increases. The Seebeck coefficients of $\mathrm{Mn}_{0.98} \mathrm{~W}_{0.2} \mathrm{Si}_{1.75} \mathrm{Ge}_{0.02}$ and $\mathrm{Mn}_{0.98} \mathrm{~W}_{0.2} \mathrm{Si}_{1.73} \mathrm{Ge}_{0.02} \mathrm{Al}_{0.02}$ peak at $650 \mathrm{~K}$ and $\mathrm{Mn}_{28.4} \mathrm{Re}_{8} \mathrm{Si}_{63.6}$ at $800 \mathrm{~K}$. Unsubstituted $\mathrm{Mn}_{36.4} \mathrm{Si}_{63.6}$ has the highest Seebeck coefficient. From Fig 2.4, it can be seen that substitution only has a minor negative effect on the Seebeck values for $\mathrm{MnSi}_{2}$.

\subsection{Thermal conductivity}

Fig. 3.1-4 show thermal conductivity as a function of temperature for all silicides. Reducing thermal conductivity is often the most significant method to increase overall figure of merit. This can result from alteration of the microstructure and/or the alloy disordering effect. $\mathrm{MnSi}_{2}$ has significantly lower thermal conductivity across all temperatures and demonstrates an abnormal downward trend with increased temperature. FeSi2 generally shows only a slight change in thermal conductivity, except for $\mathrm{Fe}_{0.95} \mathrm{Co}_{0.05} \mathrm{Si}_{2}(\mathrm{D})$ and $\mathrm{Fe}_{0.96} \mathrm{Nb}_{0.04} \mathrm{Si}_{2}$ (F) which achieve minimum thermal conductivity at $500 \mathrm{~K}$ and $750 \mathrm{~K}$, respectively.

All chromium silicides follow a similar trend of decreasing $\mathrm{k}$ to a minimum at $700 \mathrm{~K}$ of 6 $\mathrm{W} /(\mathrm{m} . \mathrm{K})$, which then increases above $700 \mathrm{~K}$. Molybdenum-doped $\mathrm{CrSi}_{2}$ was found to have a minimum $\mathrm{k}$ around $700 \mathrm{~K}$ and $\mathrm{k}$ continues to decrease at around $800 \mathrm{~K}$ for $\mathrm{Mn} / \mathrm{Al}$-doped $\mathrm{CrSi}-2$. The thermal conductivities in Fig. 3.2 show that only $\mathrm{Nb}$-doped and Co-doped $\beta$-FeSi2 show significant temperature dependence, both varying by around $2.3 \mathrm{~W} /(\mathrm{m} . \mathrm{K})$. The $\mathrm{Nb}$-doped specimen showed a great change in the thermal conductivity gradient between ranges 400 to $450 \mathrm{~K}$. 


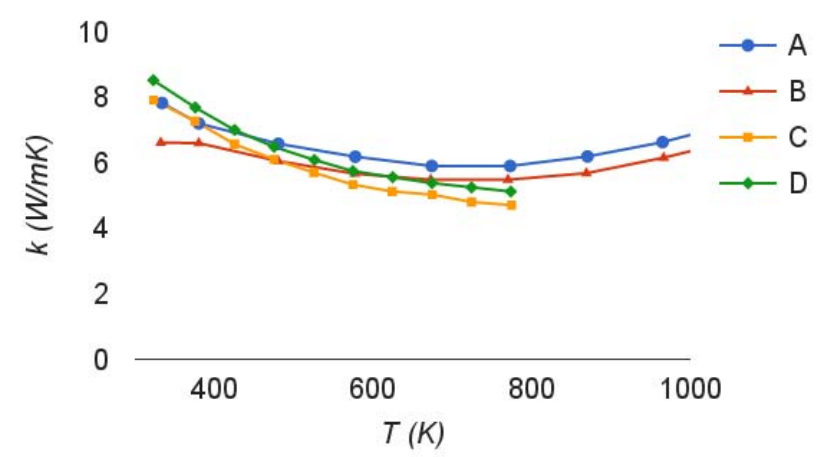

Fig. 3.1 Thermal conductivities of $\mathrm{CrSi}$ with various dopants: $\mathrm{Cr}_{0.9} \mathrm{Mo}_{0.1} \mathrm{Si}_{2}$ (A), $\mathrm{Cr}_{0.7} \mathrm{Mo}_{0.3} \mathrm{Si}_{2}$ (B), $\mathrm{Cr}_{0.975} \mathrm{Mn}_{0.025} \mathrm{Si}_{1.975} \mathrm{Al}_{0.025}$ (C) and $\mathrm{Cr}_{0.9} \mathrm{Mn}_{0.1} \mathrm{Si}_{1.9} \mathrm{Al}_{0.1}$ (D)

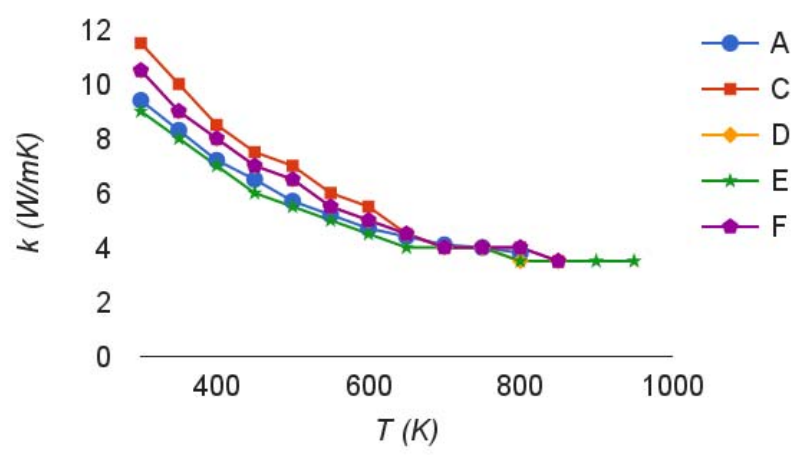

Fig. 3.3 Thermal conductivities of $\mathrm{Mg}_{2} \mathrm{Si}$ with various dopants: $\mathrm{Mg}(\mathrm{AZ})_{2} \mathrm{Si} 1$ st (A), $\mathrm{Mg}_{2} \mathrm{SiAl}_{0.01}$ (C), $\mathrm{Mg}_{2} \mathrm{SiAl}_{0.005}$ (D), Al-doped $\mathrm{Mg}_{2} \mathrm{Si} \mathrm{w} /$ glass (E) and undoped $\mathrm{Mg}_{2} \mathrm{Si}(\mathrm{F})$

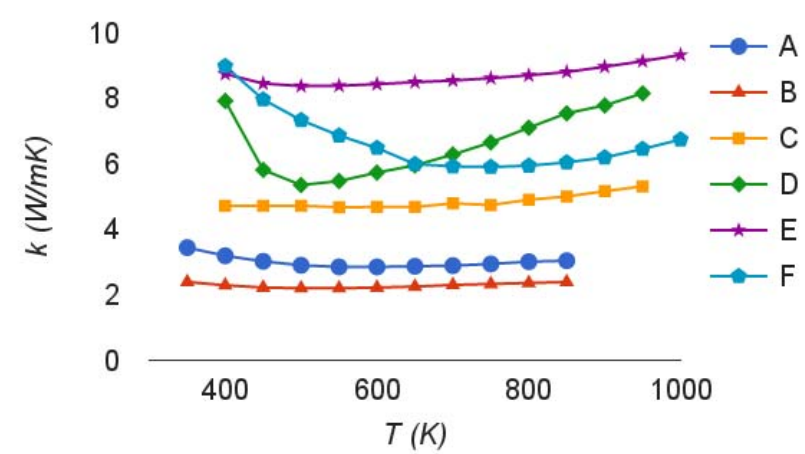

Fig. 3.2 Thermal conductivities of $\mathrm{FeSi}_{2}$ with various dopants: $\beta$ $\mathrm{FeSi}_{2}$ with $\mathrm{Sm}_{2} \mathrm{O}_{3}(\mathrm{~A}), \beta-\mathrm{FeSi}_{2}$ with $\mathrm{Er}_{2} \mathrm{O}_{3}$ (B), $\mathrm{Fe}_{0.95} \mathrm{Co}_{0.05} \mathrm{Si}_{1.958} \mathrm{Ge}_{0.042}(\mathrm{C}), \mathrm{Fe}_{0.95} \mathrm{Co}_{0.05} \mathrm{Si}_{2}$ (D), $\mathrm{Fe}_{0.94} \mathrm{Zr}_{0.06} \mathrm{Si}(\mathrm{E})$ and $\mathrm{Fe}_{0.96} \mathrm{Nb}_{0.04} \mathrm{Si}_{2}(\mathrm{~F})$

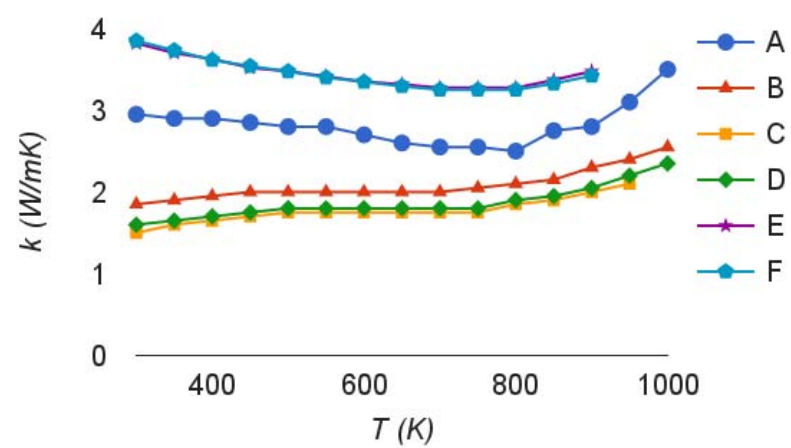

Fig. 3.4 Thermal conductivities of $\mathrm{MnSi}_{2}$ with various dopants:

$\mathrm{Mn}_{36.4} \mathrm{Si}_{63.6}(\mathrm{~A}), \mathrm{Mn}_{32.4} \mathrm{Re}_{4} \mathrm{Si}_{63.6}(\mathrm{~B}), \mathrm{Mn}_{30.4} \mathrm{Re}_{6} \mathrm{Si}_{63.6}(\mathrm{C})$,

$\mathrm{Mn}_{28.4} \mathrm{Re}_{8} \mathrm{Si}_{63.6}(\mathrm{D}), \mathrm{Mn}_{0.98} \mathrm{~W}_{0.2} \mathrm{Si}_{1.75} \mathrm{Ge}_{0.02}(\mathrm{E})$ and

$\mathrm{Mn}_{0.98} \mathrm{~W}_{0.2} \mathrm{Si}_{1.73} \mathrm{Ge}_{0.02} \mathrm{Al}_{0.02}(\mathrm{~F})$

The other doped specimens showed no apparent peaks or troughs across the temperatures. Notably, Sugihara et al.'s oxide-containing compounds maintained low thermal conductivities about $3.1 \mathrm{~W} /(\mathrm{m} . \mathrm{K})$ containing the $\mathrm{Sm}_{2} \mathrm{O}_{3}$ and $2.5 \mathrm{~W} /(\mathrm{m} . \mathrm{K})$ containing $\mathrm{Er}_{2} \mathrm{O}_{3}$. Indeed, this was the purpose of the given experiment: to reduce the thermal conductivities of $\beta-\mathrm{FeSi}_{2}$ with the use of oxides. The oxides had a significantly lower thermal conductivity, conducting as much as $74.5 \%$ less thermal energy than the rest at $400 \mathrm{~K}$.

$\mathrm{Mg}(\mathrm{AZ})_{2} \mathrm{Si}$ 2nd is omitted from Fig. 3.3 as data for thermal conductivity and ZT was unavailable. Pure Al doping produces higher thermal conductivity at lower temperatures, and all materials converge at $700 \mathrm{~K}$, therefore $\mathrm{Zn}$ and conductive glass interstitials may have greatest benefits in low-temperature applications.

Fig. 3.4 shows that $\mathrm{Mn}_{30.4} \operatorname{Re}_{6} \mathrm{Si}_{63.6}$ has the lowest thermal conductivity, followed closely by $\mathrm{Mn}_{28.4} \mathrm{Re}_{8} \mathrm{Si}_{63.6 .} \mathrm{Mn}_{30.4} \mathrm{Re}_{6} \mathrm{Si}_{63.6}$ and $\mathrm{Mn}_{28.4} \mathrm{Re}_{8} \mathrm{Si}_{63.6}$ both have a larger decrease in the thermal conductivity than undoped manganese silicide. The $\mathrm{W}$ substituted samples increase the thermal 
PAM Review 2016

conductivity significantly. The samples follow a similar pattern and increase in thermal conductivity at temperatures $>700 \mathrm{~K}$.

\subsection{Figure of merit (ZT)}

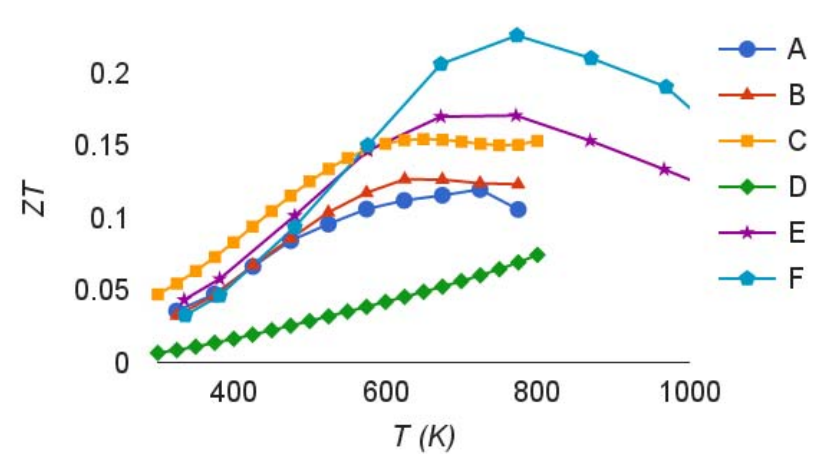

Fig. 4.1 Figure of merit of $\mathrm{CrSi}_{2}$ with various dopants:

Cro.9Mo0.1 $\mathrm{Si}_{2}$ (A), Cr0.7Mo0..3Si2 (B), Cr0.975 $\mathrm{Mn}_{0.025} \mathrm{Si}_{1.975} \mathrm{Al}_{0.025}$

(C), $\mathrm{Cr}_{0.9} \mathrm{Mn}_{0.1} \mathrm{Si}_{1.9} \mathrm{Al}_{0.1}$ (D), $\mathrm{Cr}_{0.94} \mathrm{Ti}_{0.06} \mathrm{Si}_{2}$ (E) and $\mathrm{Cr}_{0.85} \mathrm{Ti}_{0.15} \mathrm{Si}_{2}$

(F)

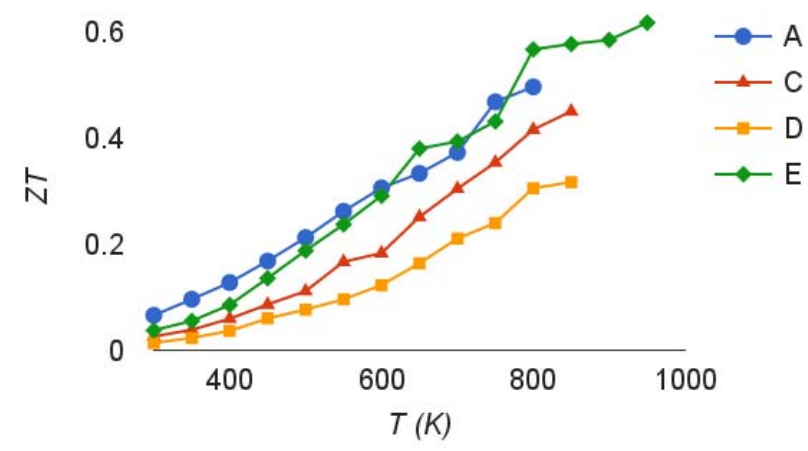

Fig. 4.3 Figure of merit of $\mathrm{Mg}_{2} \mathrm{Si}$ with various dopants:

$\mathrm{Mg}(\mathrm{AZ})_{2} \mathrm{Si}$ 1st (A), $\mathrm{Mg}_{2} \mathrm{SiAl}_{0.01}$ (C), $\mathrm{Mg}_{2} \mathrm{SiAl}_{0.005}$ (D), Al-doped $\mathrm{Mg}_{2} \mathrm{Si}$ w/ glass (E)

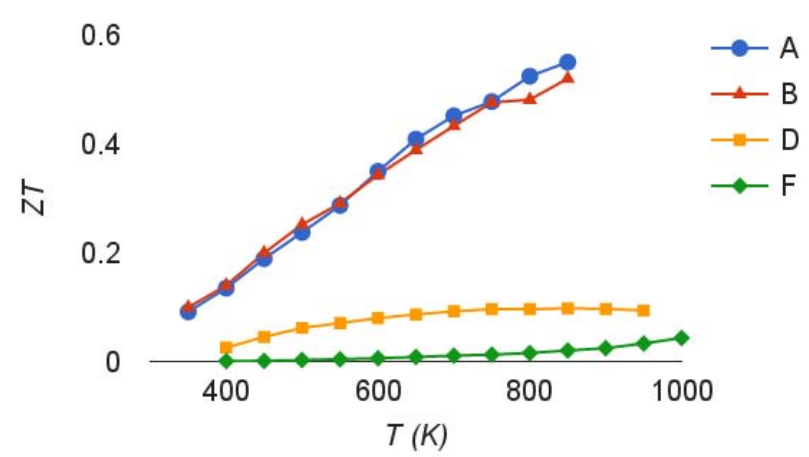

Fig. 4.1 Figure of merit of $\mathrm{FeSi}_{2}$ with various dopants: $\beta-\mathrm{FeSi}_{2}$ with $\mathrm{Sm}_{2} \mathrm{O}_{3}$ (A), $\beta$-FeSi2 with $\mathrm{Er}_{2} \mathrm{O}_{3}$ (B), $\mathrm{Fe}_{0.95} \mathrm{Co}_{0.05} \mathrm{Si}_{2}$ (D) and $\mathrm{Fe}_{0.96} \mathrm{Nb}_{0.04} \mathrm{Si}_{2}(\mathrm{~F})$

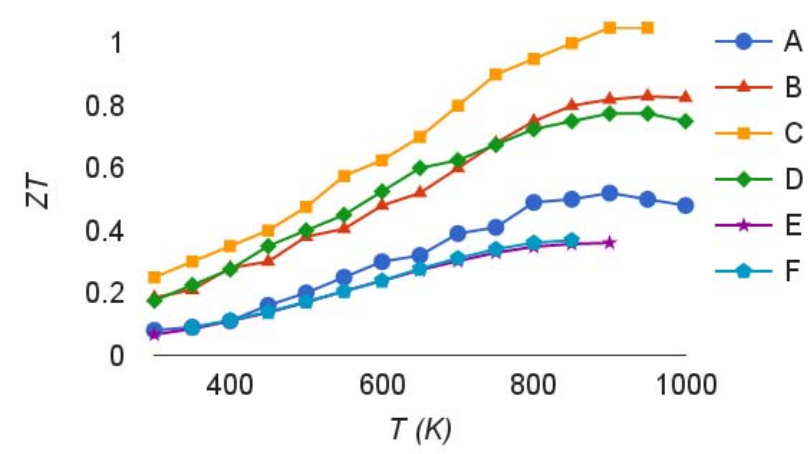

Fig. 4.4 Figure of merit of $\mathrm{MnSi}_{2}$ with various dopants:

$\mathrm{Mn}_{36.4} \mathrm{Si}_{63.6}(\mathrm{~A}), \mathrm{Mn}_{32.4} \mathrm{Re}_{4} \mathrm{Si}_{63.6}(\mathrm{~B}), \mathrm{Mn}_{30.4} \mathrm{Re}_{6} \mathrm{Si}_{63.6}(\mathrm{C})$,

$\mathrm{Mn}_{28.4} \mathrm{Re}_{8} \mathrm{Si}_{63.6}(\mathrm{D}), \mathrm{Mn}_{0.98} \mathrm{~W}_{0.2} \mathrm{Si}_{1.75} \mathrm{Ge}_{0.02}(\mathrm{E})$ and

$\mathrm{Mn}_{0.98} \mathrm{~W}_{0.2} \mathrm{Si}_{1.73} \mathrm{Ge}_{0.02} \mathrm{Al}_{0.02}(\mathrm{~F})$

Fig. 4.1-4 show figure of merit (ZT) as a function of temperature for all silicides. ZT for all the Cr substituted materials was below 0.25, as shown in Fig 4.1. CrMoxSi2 doped with high amounts of Mo $(\mathrm{x}=0.3)$ demonstrated high performance with a peak ZT of roughly 0.23 at $775 \mathrm{~K}$. $\mathrm{Cr}_{0.9} \mathrm{Mn}_{0.1} \mathrm{Si}_{1.9} \mathrm{Al}_{0.1}$ is the highest performing Mn/Al-doped TE with peak ZT of 1.3 at $625 \mathrm{~K}$. Thermal conductivity for $\mathrm{CrSi}_{2}$ and $\mathrm{Cr}_{0.94} \mathrm{Ti}_{0.06} \mathrm{Si}_{2}$ were measured at room temperature, achieving $\mathrm{k}=0.9$ and $1.64 \mathrm{~W} /(\mathrm{m} . \mathrm{K})$, respectively (Karuppaiah et al. 2013). Using linear regression an estimation of $\mathrm{k}$ was made for $\mathrm{Cr}_{0.9} \mathrm{Ti}_{0.1} \mathrm{Si}_{2}$ and $\mathrm{Cr}_{0.85} \mathrm{Ti}_{0.15} \mathrm{Si}_{2}$, producing 1.84 and $1.70 \mathrm{~W}(\mathrm{~m} . \mathrm{K})$, respectively. These values were used to estimate the ZT. Ti-doped $\mathrm{CrSi}_{2}$ was found to have a relatively low figure of merit (0.05) at $800 \mathrm{~K}$. Further study is required to confirm the results obtained from this linear regression. 
In Fig. 4.2, $\mathrm{Fe}_{0.95} \mathrm{Co}_{0.05} \mathrm{Si}_{2}$ and $\mathrm{Fe}_{0.96} \mathrm{Nb}_{0.04} \mathrm{Si}_{2}$ have extremely low $\mathrm{ZT}$ scores $(<0.15)$ across all temperatures. $\beta$-FeSi 2 with $\mathrm{Sm}_{2} \mathrm{O}_{3}$ and $\mathrm{Er}_{2} \mathrm{O}_{3}$ showed exceptionally greater $\mathrm{ZT}$ across all temperatures, reaching 0.56 at $868 \mathrm{~K}$ and 0.54 at $877 \mathrm{~K}$, respectively. Sugihara et al. hypothesised that this could be owed to the relationship between the standard reduction potential, thermal conductivities and electrical conductivities, specifically of the rare earth oxides used in the experiment $\left(\mathrm{Sm}_{2} \mathrm{O}_{3}\right.$ and $\left.\mathrm{Er}_{2} \mathrm{O}_{3}\right)$. The standard reduction potential is defined as the potential for atoms to convert between their oxidation states. This property is indeed present in all silicides, but while subtle, may be the reason for improved thermal and electrical conductivities of these oxide-addition TE materials.

Fig. 4.3 shows a positive gradient for all materials across all temperatures. Al-doped $\mathrm{Mg}_{2} \mathrm{Si}$ w/ glass shows large ZT at high temperatures $(>800 \mathrm{~K})$ as it maintains a high Seebeck coefficient due to the fact that conductive glass acts as a physical interstitial (crack filling) rather than a solute (Satyala, N.T., Krasinski, J.S. \& Vashaee, D. 2012). Mg(AZ) 2 Si shows largest ZT for mid to low temperatures $(<750 \mathrm{~K})$. Similar to $\mathrm{FeSi}_{2}$ oxides, all magnesium silicides maintain a large positive $\mathrm{ZT}$ gradient at high temperatures.

Fig. 4.4 shows manganese silicides behave in a similar pattern to each other, maintaining a positive ZT gradient between 300 and $900 \mathrm{~K}$. $\mathrm{Mn}_{30.4} \mathrm{Re}_{6} \mathrm{Si}_{63.6}$ has the highest $\mathrm{ZT}$ value for all temperatures with a maximum ZT at $900 \mathrm{~K}$ with a score of $1.05 . \mathrm{Mn}_{36.4-\mathrm{x}} \mathrm{Re}_{\mathrm{x}} \mathrm{Si}_{63.6}$ with $\mathrm{x}=4,6$ and 8 shows a significant improvement in ZT score compared to the undoped material. Doping of Re into the $\mathrm{MnSi}_{2}$ material leads to a positive increase in ZT. The material $\mathrm{Mn}_{30.4} \mathrm{Re}_{6} \mathrm{Si}_{63.6}$ shows the highest ZT score, with $\mathrm{Mn}_{32.4} \mathrm{Re}_{4} \mathrm{Si}_{63.6}$ and $\mathrm{Mn}_{28.4} \mathrm{Re}_{8} \mathrm{Si}_{63.6}$ producing lower ZT scores, suggesting that there is an optimum amount of Re substitution for improving ZT score. Tungsten-germanium manganese silicides showed poor results due to high thermal conductivity.

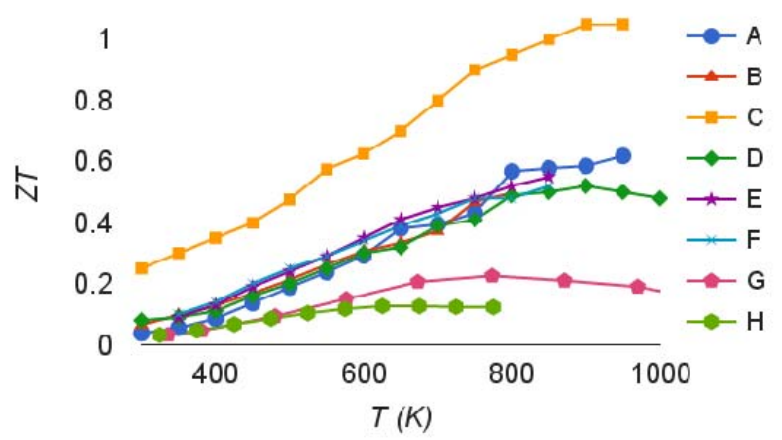

Fig. 5 Figure of Merit of selected materials: Al-doped $\mathrm{Mg}_{2} \mathrm{Si}$ w/ glass (A), $\mathrm{Mg}(\mathrm{AZ})_{2} \mathrm{Si}(\mathrm{B}), \mathrm{Mn}_{30.4} \mathrm{Re}_{6} \mathrm{Si}_{63.6}(\mathrm{C}), \mathrm{Mn}_{36.4} \mathrm{Si}_{63.6}$ (D), $\beta$ $\mathrm{FeSi}_{2}$ w/ $\mathrm{Sm}_{2} \mathrm{O}_{3}(\mathrm{E}), \beta-\mathrm{FeSi}_{2} \mathrm{w} / \mathrm{Er}_{2} \mathrm{O}_{3}(\mathrm{~F}), \mathrm{Cr}_{0.7} \mathrm{Mo}_{0.3} \mathrm{Si}_{2}(\mathrm{G})$, and $\mathrm{Cr}_{0.975} \mathrm{Mn}_{0.025} \mathrm{Si}_{1.975} \mathrm{Al}_{0.025}(\mathrm{H})$.

Fig. 5 shows the figure of merit (ZT) as a function of temperature for the best performing silicides $\left(\mathrm{CrSi}_{2}\right.$ substituted with $\mathrm{Mo}$ and $\mathrm{Mn} / \mathrm{Al}, \mathrm{FeSi}_{2}$ with additional rare earth oxides, Al-doped $\mathrm{MgSi}$ w/ glass and $\mathrm{Al} / \mathrm{Zn}$ and $\mathrm{MnSi}_{2}$ substituted with and without $\mathrm{Re}$ ). Chromium silicides reach peak $\mathrm{ZT} \leq 0.1$ (between $600-800 \mathrm{~K}$ ) due to all thermodynamic components reaching a $\mathrm{max} / \mathrm{min}$ in this range. Al $\mathrm{Mg}_{2} \mathrm{Si}$ w/ glass, $\mathrm{Mn}_{36.4} \mathrm{Si}_{63.6}, \mathrm{Mg}(\mathrm{AZ})_{2} \mathrm{Si}$ 1st, $\mathrm{FeSi}_{2}$ with $\mathrm{Er}_{2} \mathrm{O}_{3}$ and $\mathrm{FeSi}_{2}$ with $\mathrm{Sm}_{2} \mathrm{O}_{3}$ maintain similar ZT scores between 400 and $800 \mathrm{~K}$. Mn36.4Si63.6 has a peak ZT value at $900 \mathrm{~K}$. $\mathrm{Mn}_{30.4 \mathrm{Re}_{6} \mathrm{Si} 63.6}$ has a significantly higher score across all temperatures, which is attributed to the fact that Yamamoto et al. determined how to surpass the theoretical solubility limit using a special 


\section{PAM Review 2016}

technique of arc melting, followed by liquid quenching (Yamamoto et al. 2016). Rhenium substitution improves thermoelectric properties across the board and thermal conductivity is reduced significantly (3 to $1.5 \mathrm{~W} /(\mathrm{m} . \mathrm{K})$.

\section{CONCLUSION}

The rhenium-substituted manganese silicide, $\mathrm{Mn}_{30.4} \mathrm{Re}_{6} \mathrm{Si}_{63.6}$ had a figure of merit curve double that of the other silicides. Perhaps the most influential aspect lies in the method of its synthesis. $\mathrm{Mn}_{30.4} \operatorname{Re}_{6} \mathrm{Si}_{63.6}$ was formed through arc melting its constituent materials, then supersaturation by liquid quenching, allowing for an abnormally high ZT. Indeed, supersaturation via liquid quenching may be the key to further improving the properties of silicides. Oxide addition to $\beta$-FeSi2 produced much higher ZT scores than $\mathrm{Co}$ - and $\mathrm{Nb}$-doped $\beta$-FeSi2. Further investigation could be made into the performance of oxides with other solvents as well as exploring their associated optimal concentration levels.

It was found that chromium silicides are most effective at a temperature range of $600-800 \mathrm{~K}$, and undoped magnesium silicides are most effective around $900 \mathrm{~K}$. These silicides would be effective TEGs in environments with a stable temperature around 600 to $900 \mathrm{~K}$, such as automotive exhausts.

Our meta-study demonstrates that silicon-based thermoelectric materials show significant room for improvement. Achieving the most efficient power generation from heat greatly depends on factors such as Seebeck coefficient, thermal conductivity and electrical conductivity. We suggest that these thermoelectric properties can be further optimised in silicides by supersaturation via liquid quenching, and/or the addition of oxides, enabling silicides to attain larger figure of merit at medium to hightemperature ranges.

\section{ACKNOWLEDGEMENTS}

Jurgen Schulte, 'Energy Science and Technology (68412)' Subject Coordinator, Faculty of Science, University of Technology, Sydney

\section{REFERENCES}

Abeles, B., 1963, 'Lattice Thermal Conductivity of Disordered Semiconductor Alloys at High Temperatures', Phys. Rev., vol. 131, no. 5, pp. 1906-1911. Available at: $<$ http://link.aps.org/doi/10.1103/PhysRev.131.1906>. http://dx.doi.org/10.1103/PhysRev.131.1906

Arohatgi.info. (2016). WebPlotDigitizer - Copyright 2010-2016 Ankit Rohatgi. [online] Available at: $<$ http://arohatgi.info/WebPlotDigitizer/app/> [Accessed 23 May 2016].

Aswal, D.K., Basu, R. \& Singh, A. 2016, 'Key issues in development of thermoelectric power generators: High figure-of-merit materials and their highly conducting interfaces with metallic interconnects', Energy Conversion and Management, vol. 114, pp. 50-67. doi: http://dx.doi.org/10.1016/j.enconman.2016.01.065

Battiston, S., Fiameni, S., Saleemi, M., Boldrini, S., Famengo, A., Agresti, F., Stingaciu, M., Toprak, M. S., Fabrizio, M., Barison, S., 2013, 'Synthesis and characterization of Al-Doped Mg2Si 
thermoelectric materials', Journal of Electronic Materials, vol. 42, no. 7, pp. 1956-1959. doi: http://dx.doi.org/10.1007/s11664-013-2482-6

Fedorov, M.I., 2009. 'Thermoelectric Silicides: Past, Present and Future', Journal of Thermoelectricity, vol. 2, pp.51-60. Available at: http://archive.nbuv.gov.ua/portal/Natural/TE/2009_2/Fed.eng.pdf.

Frobenius, F., Gaiser, G., Rusche, U. \& Weller, B. 2016, 'Thermoelectric Generators for the Integration into Automotive Exhaust Systems for Passenger Cars and Commercial Vehicles', Journal of Electronic Materials, vol. 45, no. 3, pp. 1433-40. doi: http://dx.doi.org/10.1007/s11664$\underline{015-4059-\mathrm{Z}}$

GNP Industry Alliance, 'The High Temperature Gas-Cooled Reactor (HTGR) - Safe, Clean and Sustainable Energy for the Future', accessed 24 May 2016, $<$ http://www.ngnpalliance.org/index.php/htgr>. 2010 NGNP Industry Alliance.

Gorsse, S.P.S. \& Chevalier, U.A.B., 2013, 'Effect of co-substitution of Mn and Al on thermoelectric properties of chromium disilicide', Journal of Materials Science, vol. 48, no. 1, pp. 227-231. doi: http://dx.doi.org/10.1007/s10853-012-6732-4

Hu, X., Mayson, D. \& Barnett, M.R., 2014, 'Synthesis of Mg2Si for thermoelectric applications using magnesium alloy and spark plasma sintering', Journal of Alloys and Compounds, vol. 589, pp. 485490. Available at: doi: http://dx.doi.org/10.1016/j.jallcom.2013.11.092

IEA.org. (2016). IEA - Report. [online] Available at:

$<$ http://www.iea.org/statistics/statisticssearch/report/?year=2013\&country=AUSTRALI\&product= Balances> [Accessed 22 May 2016].

Ito. M. Nagai, H. Katsuyama, S. Majima, K. 2001, 'Effects of Ti, $\mathrm{Nb}$ and $\mathrm{Zr}$ doping on thermoelectric performance of $\beta$-FeSi2', Journal of Alloys and Compounds, vol. 315, no. 1-2, pp. 251-258. doi: http://dx.doi.org/10.1016/S0925-8388(00)01285-8

Karuppaiah, S. Beaudhuin, M. Viennois, R. 2013, 'Investigation on the thermoelectric properties of nanostructured $\mathrm{Cr}_{1-\mathrm{x}} \mathrm{Ti}_{\mathrm{x}} \mathrm{Si}_{2}$ ', Journal of Solid State Chemistry, vol. 199, pp. 90-95. doi: http://dx.doi.org/10.1016/j.jssc.2012.12.004

Kim, S.W., Cho, M.K., Mishima, Y., Choi., D.C., 2003, 'High temperature thermoelectric properties of p- and n-type $\beta$-FeSi2 with some dopants', Intermetallics, vol. 11, no. 5, pp. 399-405. doi: http://dx.doi.org/10.1016/S0966-9795(03)00020-7

Kittel, C. Introduction to solid state physics, 8th ed.; 2005 [ISBN 0-471-41526- X].

Ohishi, Y. Miyazaki, Y. Muta, H. Kurosaki, K. Yamanaka, S. 2015, 'Thermoelectric properties of Cr 1 ${ }_{x} \mathrm{Mo}_{x} \mathrm{Si}_{2}$ ', Journal of Physics and Chemistry of Solids, vol. 87, pp. 153-157. doi: http://dx.doi.org/10.1016/j.jpcs.2015.08.017 
Ozden, A., Kandemir, A., Ay, F., Perkgoz, N. K., Sevik, C., 2015, 'Thermal Conductivity Suppression in Nanostructured Silicon and Germanium Nanowires', Journal of Electronic Materials, vol. 45, no. 3, pp. 1594-1600. doi: http://dx.doi.org/10.1007/s11664-015-4127-4

Rowe, D.M. 1995, CRC handbook of thermoelectrics, CRC press. doi: http://dx.doi.org/10.1201/9781420049718

Satyala, N.T. Krasinski, J.S. \& Vashaee, D., 2012, 'Thermoelectric properties of Mg2Si doped with Bi and Al with conductive glass inclusion', 2012 IEEE Green Technologies Conference, pp. 1-5. doi: http://dx.doi.org/10.1109/GREEN.2012.6200960

Snyder, G.J. \& Toberer, E.S. 2008, 'Complex thermoelectric materials', Nature materials, vol. 7, no. 2, pp. 105-14. doi: http://dx.doi.org/10.1038/nmat2090

Sugihara, S. Morikawa, K. 2011, 'Improved Thermoelectric Performances of Oxide-Containing FeSi2', Materials Transactions, vol. 52, no. 8, pp. 1526-1530. doi:

http://dx.doi.org/10.2320/matertrans.E-M2011812

Taylor, S.R., 1964, 'Abundance of chemical elements in the continental crust: a new table', Geochimica et Cosmochimica Acta, vol. 28, no. 8, pp. 1273-1285. doi: http://dx.doi.org/10.1016/0016-7037(64)90129-2

Truong, N. D.Y., Berthebaud, D., Gascoin, F. \& Kleinke, H. 2015, 'Molybdenum, Tungsten, and Aluminium Substitution for Enhancement of the Thermoelectric Performance of Higher Manganese Silicides', Journal of Electronic Materials, vol. 44, no. 10, pp. 3603-11. doi: http://dx.doi.org/10.1007/s11664-015-3854-x

Yamamoto, A., Ghodke, S., Miyazaki, H., Inukai, M., Nishino, Y., Matsunami, M. \& Takeuchi, T. 2016, 'Thermoelectric properties of supersaturated Re solid solution of higher manganese silicides', Japanese Journal of Applied Physics, vol. 55, no. 2, pp. 4.http://dx.doi.org/10.7567/JJAP.55.020301

Zhao, L.D., Wu, H.J., Hao, S.Q., Wu, C.I., Zhou, X.Y., Biswas, K., He, J.Q., Hogan, T.P., Uher, C., Wolverton, C., Dravid, V.P. \& Kanatzidis, M.G. 2013, 'All-scale hierarchical thermoelectrics: $\mathrm{MgTe}$ in $\mathrm{PbTe}$ facilitates valence band convergence and suppresses bipolar thermal transport for high performance', Energy \& Environmental Science, vol. 6, no. 11, pp. 3346-55. doi: http://dx.doi.org/10.1039/c3ee42187b 